\title{
Absorption of Sulfur Dioxide by Tetraglyme-Sodium Salt Ionic Liquid
}

\author{
Qiang $\mathrm{Xu}$, Wei Jiang, Jianbai Xiao and Xionghui Wei *(D) \\ College of Chemistry and Molecular Engineering, Peking University, Beijing 100871, China; \\ 1401210206@pku.edu.cn (Q.X.); 1501210153@pku.edu.cn (W.J.); glorioussoviet@126.com (J.X.) \\ * Correspondence: xhwei@pku.edu.cn or 0006164441@pku.edu.cn; Tel.: +86-010-6275-1529
}

Received: 6 December 2018; Accepted: 7 January 2019; Published: 26 January 2019

check for updates

\begin{abstract}
A series of tetraglyme-sodium salt ionic liquids have been prepared and found to be promising solvents to absorb $\mathrm{SO}_{2}$. The experiments here show that [Na-tetraglyme][SCN] ionic liquid has excellent thermal stability and a $30 \%$ increase in $\mathrm{SO}_{2}$ absorption capacity compared to other sodium salt ionic liquids and the previously studied lithium salt ionic liquids in terms of molar absorption capacity. The interaction between $\mathrm{SO}_{2}$ and the ionic liquid was concluded to be physical absorption by IR and NMR.
\end{abstract}

Keywords: $\mathrm{SO}_{2}$ removal; ionic liquid; recyclable absorption; tetraglyme

\section{Introduction}

$\mathrm{SO}_{2}$ (sulfur dioxide) is considered to be one of the inevitable atmospheric pollutants of industrial production. $\mathrm{SO}_{2}$ has a number of environmental and health issues and is identified as one of the most important variables to cause hazy weather [1,2]. Thus, the control of $\mathrm{SO}_{2}$ emission has been a serious global concern for the last century. As more countries pay extensive attention to environmental protection, limits of $\mathrm{SO}_{2}$ emissions in flue gas are becoming more stringent. Among the desulfurization technologies, calcium-based FGD technology is a popular method [3-5]. However, the operating cost is an issue. Furthermore, a large amount of gypsum formed in the FGD process has low quality, often clogs the pipeline, and is a secondary pollutant since its permeation is harmful to the soil and groundwater. Therefore, research on the removal of $\mathrm{SO}_{2}$ by effective solvents via absorbing-stripping processes has always been a topic of interest. In particular, the development of efficient, low cost, and low volatility solvents is the key to the success of this process.

Organic solvents have recently been used for the removal of $\mathrm{SO}_{2}$ [6,7]. However, different organic solvents have their own shortcomings. For example, although organic amines have excellent absorption performance, they are difficult to regenerate. Regarding glycols, almost complete regeneration can be carried out at low temperature, but the absorption capacity is lower than other organic solvents. Glymes were found to have better $\mathrm{SO}_{2}$ absorption performance than glycols due to the physical interaction between $\mathrm{S}$ atoms and $\mathrm{O}$ atoms [8,9]. However, high volatility is one of the major disadvantages of glymes.

Ionic liquids, as a new type of solvent have been further developed for their irreplaceable advantages, such as low saturated vapor pressure and high thermal and chemical stability [10]. Ionic liquids have been used in catalytic processes [11], material synthesis [12], gas detection [13], and separation of mixtures, such as $\mathrm{CO}_{2}$ [14], $\mathrm{H}_{2} \mathrm{~S}$ [15], $\mathrm{NO}_{2}$ [16], and $\mathrm{CH}_{4}$ [17] absorption. Different ionic liquids, including guanidinium [18-20], imidazolium [21-23], hydroxyl ammonium [24,25], pyridinium [26], tetrabutyl ammonium [27], and phosphonium [28] have been used in $\mathrm{SO}_{2}$ absorption. These ionic liquids have disadvantages, such as high cost, complexity in preparation, difficulty in regeneration, and so on. In addition, various ether-functionalized [29-31] and anion-functionalized [32-34] ionic liquids were 
synthesized to improve the $\mathrm{SO}_{2}$ absorption capacity and selectivity. However, most of those ionic liquids are prepared by complicated processes with high cost. This can be a significant obstacle when the ionic liquids' effective industrial practice is seriously considered. An easily-prepared ionic liquid would have obvious advantages in the industrialization of $\mathrm{SO}_{2}$ absorbents.

A series of glyme-lithium salt ionic liquids have been prepared and studied, and the simple synthetic method explored another path for the development of similar ionic liquids [35]. The interaction between $\mathrm{Na}^{+}$and organic solvents, such as crown ether [36], ethylene glycol [37], and acetamide [38], has been extensively studied recently. It was found that sodium salt ionic liquids can be formed by sodium salt dissolution in glymes $[39,40]$.

In this paper, a series of sodium salt ionic liquids were synthesized and the performance of the ionic liquids were studied. It is noticeable that [Na-tetraglyme][SCN] ionic liquid has about $30 \%$ better absorption capacity than tetraglyme (G4), other tetraglyme-sodium salt ionic liquids, and the glyme-lithium salt ionic liquids. Moreover, the mechanism of the interaction between $\mathrm{SO}_{2}$ and the ionic liquids was investigated by IR and NMR.

\section{Experimental Section}

\subsection{Preparation of Ionic Liquids}

The preparation of the ionic liquid was as follows: first, different sodium salts and tetraglyme were mixed at the stoichiometric ratio of 1:1 and then heated to a temperature of $303 \mathrm{~K}$ for $6 \mathrm{~h}$ while maintaining sufficient agitation. The solution was then dried in a vacuum drying chamber for $48 \mathrm{~h}$. The resulting solution was transparent yellowish or colorless. The cation of the ionic liquid formed at this time is a supramolecular system consisting of sodium ions and neutral tetraglyme molecules. The anions of the ionic liquids are still the anions initially introduced by the sodium salts. The difference between these ionic liquids is mainly manifested in anions, and the cations have the same structure.

\subsection{Absorption and Desorption of $\mathrm{SO}_{2}$}

The absorption experiment was carried out under 1 bar with a $\mathrm{SO}_{2}$ partial pressure of 1 bar and a flow rate of $100 \mathrm{~mL} / \mathrm{min}$. During the regeneration experiment, regeneration was carried out for $30 \mathrm{~min}$ at $80^{\circ} \mathrm{C}$ by nitrogen stripping, and the flow rate was $100 \mathrm{~mL} / \mathrm{min}$.

\section{Results and Discussion}

\subsection{Properties of Ionic Liquids}

MS, ${ }^{1} \mathrm{H}-\mathrm{NMR},{ }^{13} \mathrm{C}-\mathrm{NMR}$, and IR were used to identify the structures of the tetraglyme- $\mathrm{Na}^{+}$salt ionic liquids. Low resolution MS data for an ionic liquid consisting of $\mathrm{NaSCN}$ and tetraglyme is shown in Figure S1 in Supporting Information. It can be clearly seen that the [Na-tetraglyme][SCN] ionic liquid has a cationic molecular weight of about 245.1, which is the sum of the molecular weight of tetraglyme (222.28) and the molecular weight of sodium ion (22.99). This means that sodium ion and tetraglyme molecular form the supramolecular structure as the cation of these ionic liquids (shown in Figure 1).

The ${ }^{1} \mathrm{H}-\mathrm{NMR}$ data of tetraglyme and [Na-tetraglyme][SCN] ionic liquid are shown in Figure 2. After the form of the ionic liquid, the chemical shift has undergone a significant change, which is mainly due to the interaction of the sodium ion with the oxygen atoms in the tetraglyme molecular to reduce the deshielding effect of the oxygen atom. In contrast, the chemical shifts of the carbon atoms are basically unchanged after the form of the ionic liquid (seen in the ${ }^{13} \mathrm{C}-\mathrm{NMR}$ data in Figure 3). This means that the carbon atoms may not be involved in the interaction with the sodium ions in the formation of the supramolecular structure. The NMR data further confirmed the cationic structure of the ionic liquid (shown in Figure 1). 


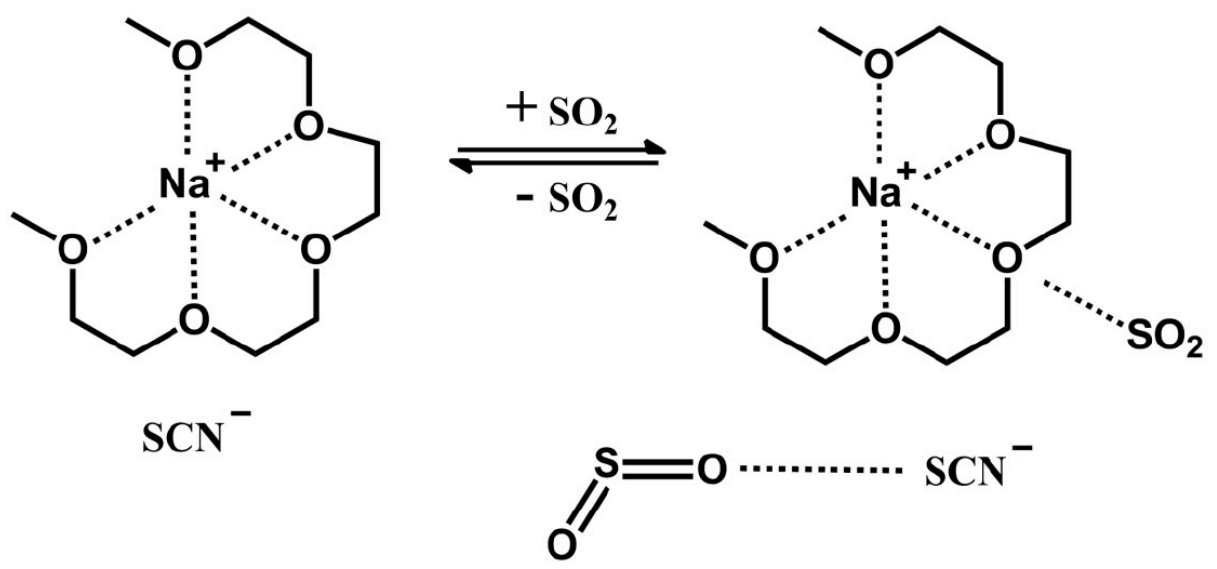

Figure 1. Structure of [Na-tetraglyme $]^{+}$ion before and after $\mathrm{SO}_{2}$ absorption.

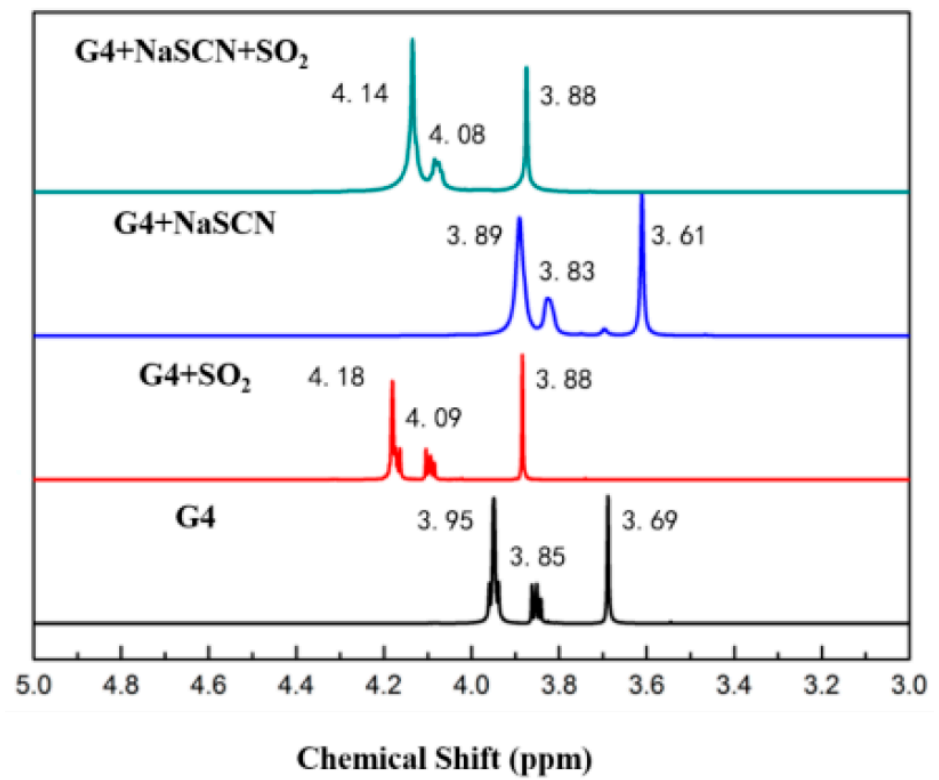

Figure 2. ${ }^{1} \mathrm{H}-\mathrm{NMR}$ spectra of tetraglyme, tetraglyme after $\mathrm{SO}_{2}$ absorption, [Na-tetraglyme][SCN] and [Na-tetraglyme][SCN] after $\mathrm{SO}_{2}$ absorption, with $\mathrm{CDCl}_{3}$ as an external reference.

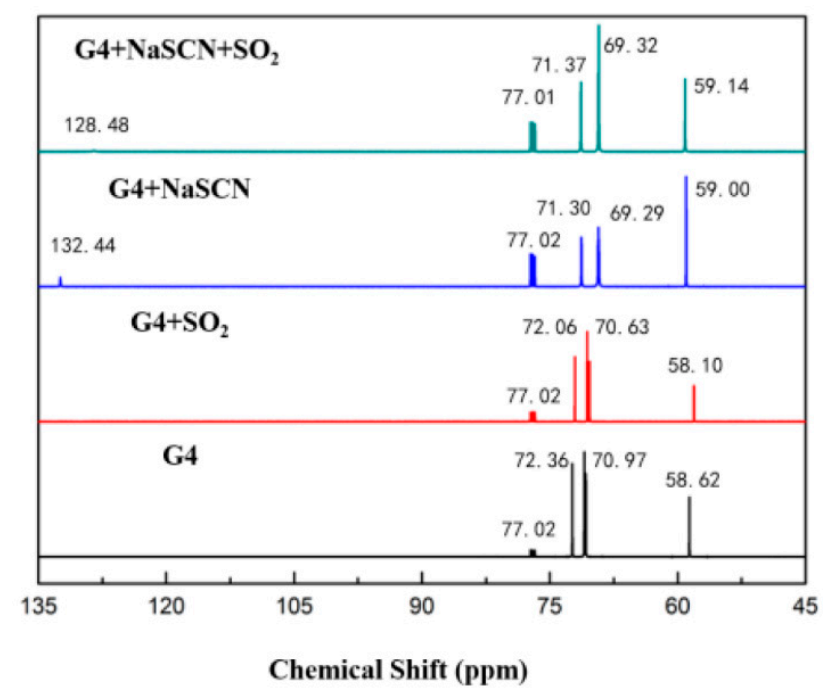

Figure 3. ${ }^{13} \mathrm{C}-\mathrm{NMR}$ spectra of tetraglyme, tetraglyme after $\mathrm{SO}_{2}$ absorption, [Na-tetraglyme][SCN] and [Na-tetraglyme][SCN] after $\mathrm{SO}_{2}$ absorption, with $\mathrm{CDCl}_{3}$ as an external reference. 
It can be seen from the IR spectra in Figure 4 that when tetraglyme forms ionic liquid with NaSCN, there is no significant shift in the $\mathrm{C}-\mathrm{O}$ vibration peak at $1110 \mathrm{~cm}^{-1}$ and the $\mathrm{C}-\mathrm{C}$ vibration peak at $1430 \mathrm{~cm}^{-1}$. A closer comparison of the spectra of the two materials reveals another difference: the ionic liquid has a distinct absorption peak at $2064 \mathrm{~cm}^{-1}$, which is the absorption peak of $\mathrm{SCN}^{-}$.

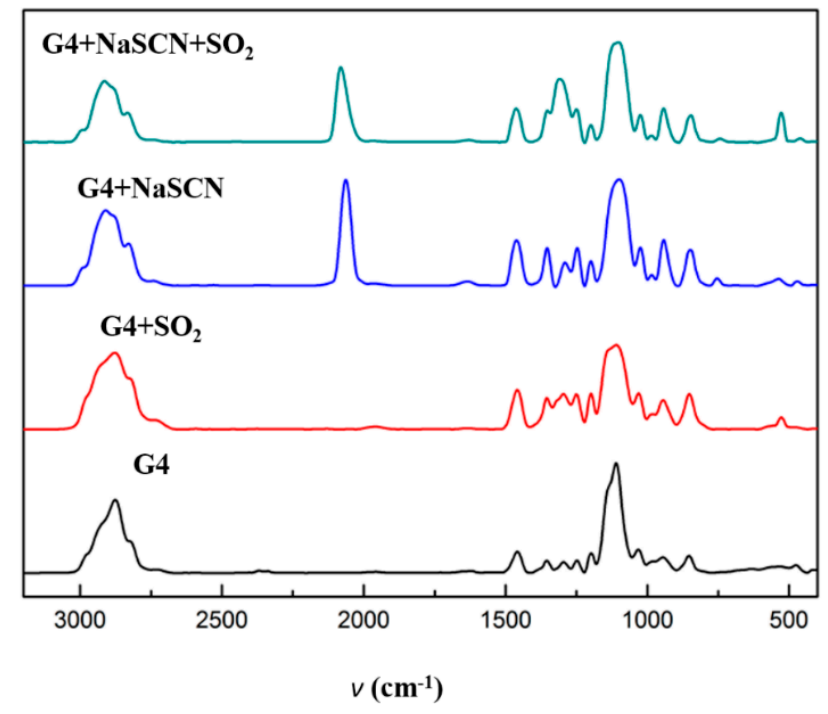

Figure 4. IR spectra of tetraglyme and [Na-tetraglyme][SCN] before and after $\mathrm{SO}_{2}$ absorption.

An important purpose of tetraglyme for forming ionic liquids is to increase the thermal stability of the absorbing solvents. As seen from Figure 5, the thermal stability of [Na-tetraglyme][SCN] ionic liquid is significantly improved compared to tetraglyme. The $T_{d}$ increases from $371 \mathrm{~K}$ of tetraglyme to $433 \mathrm{~K}$ of [Na-tetraglyme][SCN] ionic liquid. In addition, the mass of [Na-tetraglyme][SCN] ionic liquid remains stable at $373 \mathrm{~K}$, while the tetraglyme is linearly reduced (seen from Figure S2). This means that [Na-tetraglyme][SCN] ionic liquid can be applied to $\mathrm{SO}_{2}$ absorbing and regeneration without an obvious solvent loss when operating in the absorption and regeneration temperature range (i.e., $293 \mathrm{~K}$ to $353 \mathrm{~K}$ ), which undoubtedly opens up the possibility of industrial application of those ionic liquids.

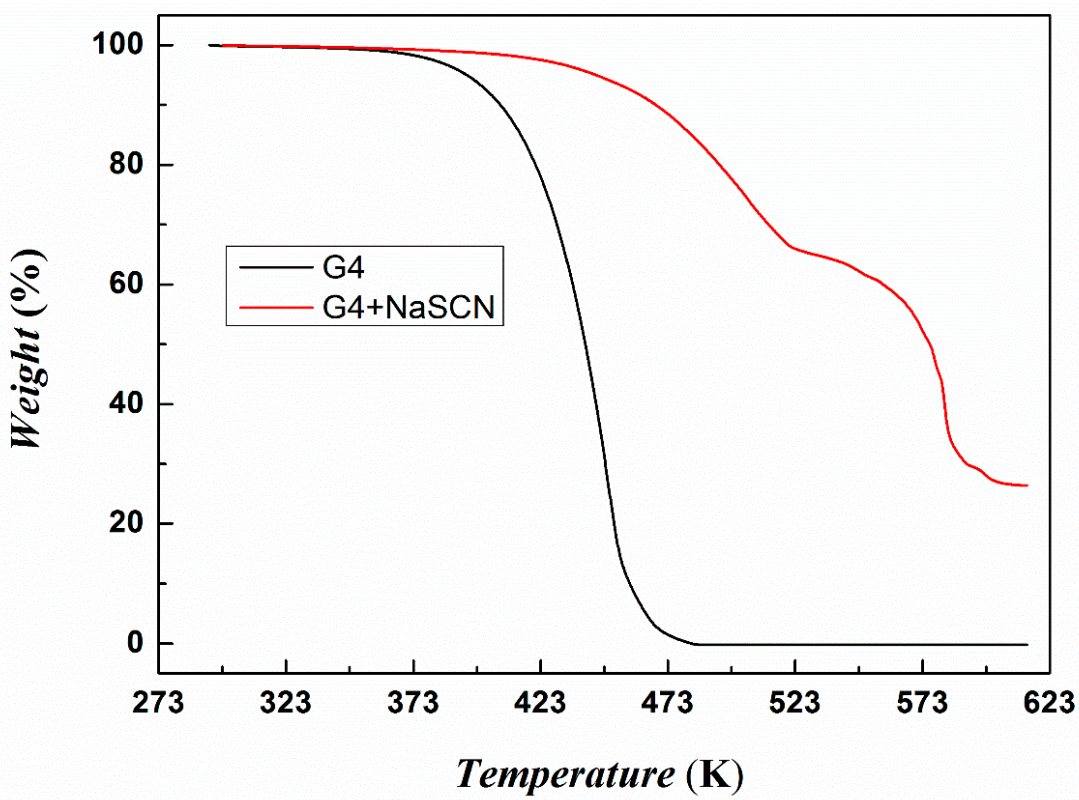

Figure 5. Thermal gravimetric analysis of tetraglyme and [Na-tetraglyme][SCN]. 


\subsection{Absorption Capacity of Ionic Liquids}

Figure 6 shows a comparison of the absorption of $\mathrm{SO}_{2}$ by tetraglyme and [Na-tetraglyme][SCN] ionic liquid at different temperatures at one atmosphere. A comparison of the absorption at each temperature indicates a significant increase in the amount of $\mathrm{SO}_{2}$ absorbed by the ionic liquid compared to tetraglyme alone. For example, one mol [Na-tetraglyme][SCN] ionic liquid can absorb $2.72 \mathrm{~mol}$ $\mathrm{SO}_{2}$ at $293 \mathrm{~K}$, while tetraglyme can absorb $2.10 \mathrm{~mol} \mathrm{SO}_{2}$ under the same conditions. This means the absorption capacity of the ionic liquid is improved by about $30 \%$ over tetraglyme. Moreover, the absorption capacity of both tetraglyme and the ionic liquid decreases as the temperature increases, because $\mathrm{SO}_{2}$ tends to exist in the form of gas in high temperature.

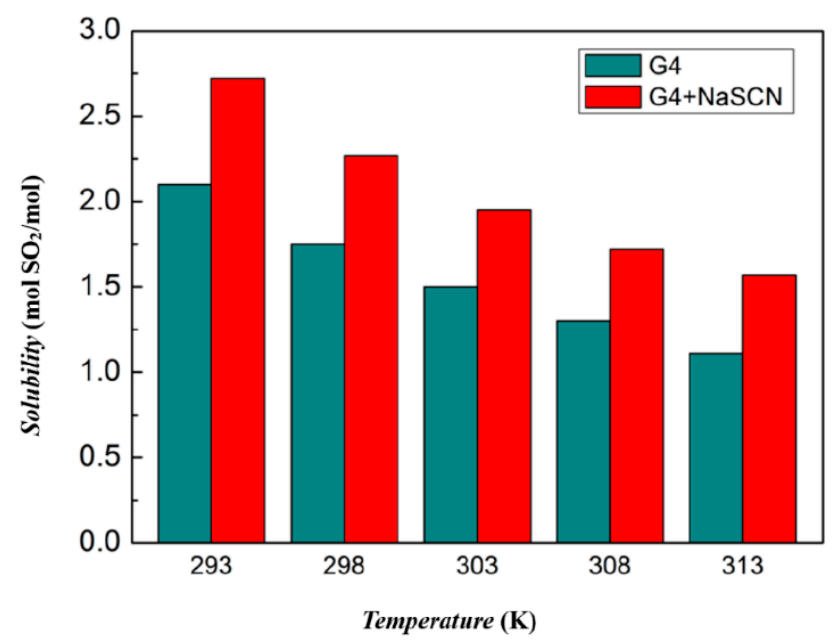

Figure 6. $\mathrm{SO}_{2}$ absorption capacities of tetraglyme and [Na-tetraglyme][SCN] at different temperatures with the pressure of $\mathrm{SO}_{2}$ equal to 1 bar.

The absorption capacity of tetraglyme and [Na-tetraglyme][SCN] ionic liquid under different partial pressures of $\mathrm{SO}_{2}$ was also investigated and the results are shown in Figure 7. As the partial pressure of $\mathrm{SO}_{2}$ increases, the absorption capacity for $\mathrm{SO}_{2}$ of both tetraglyme and [Na-tetraglyme][SCN] ionic liquid increases, and this increase is linear. At the same time, the absorption capacity of [Na-tetraglyme][SCN] ionic liquid is always higher than that of tetraglyme alone at the same temperature and partial pressures.

Figure 8 shows a comparison of the $\mathrm{SO}_{2}$ absorption capacity of ionic liquids formed by tetraglyme with several different anionic salts. The saturated $\mathrm{SO}_{2}$ absorption of tetraglyme, [Na-tetraglyme][ $\left.\mathrm{BF}_{4}\right]$ and [Na-tetraglyme][ClO$\left.{ }_{4}\right]$ ionic liquid is $2.10,2.11$, and $2.13 \mathrm{~mol}$ per mol solvent, respectively, at the temperature of $293 \mathrm{~K}$ and 1 bar. Correspondingly, [Li-tetraglyme][NTf 2 ] has a similar $\mathrm{SO}_{2}$ absorption capacity to the above ionic liquids of $2.12 \mathrm{~mol}$ per mol solvent [35]. As a comparison, the saturated absorption of [Na-tetraglyme][SCN] ionic liquid is $2.72 \mathrm{~mol}$ per mol solvent, which is about $30 \%$ higher than that of other anionic ionic liquids under the same conditions. It suggests that the type of anion has an important influence on the $\mathrm{SO}_{2}$ absorption capacity of the ionic liquid, which is different from previous research [35]. The anion $\mathrm{SCN}^{-}$plays an important role in the absorption of $\mathrm{SO}_{2}$.

In addition, the effects of oxygen and water on the absorption of ionic liquids have also been studied. The results show that oxygen has little effect on the $\mathrm{SO}_{2}$ absorption capacity of [Na-tetraglyme][SCN] ionic liquid, as shown in Figure S3. The effect of ionic liquids with different water contents on the absorption capacity of $\mathrm{SO}_{2}$ is shown in the Figure S4. As the water content in the ionic liquid increases, the absorption capacity of the ionic liquid increases slightly, rather than decreases. This shows that the participation of water does not hinder the ability of ionic liquids to absorb $\mathrm{SO}_{2}$. In summary, the above experiments show that such ionic liquids have good oxygen and water resistance, which is also a required characteristic that can be considered for future industrial desulfurization absorbents. 


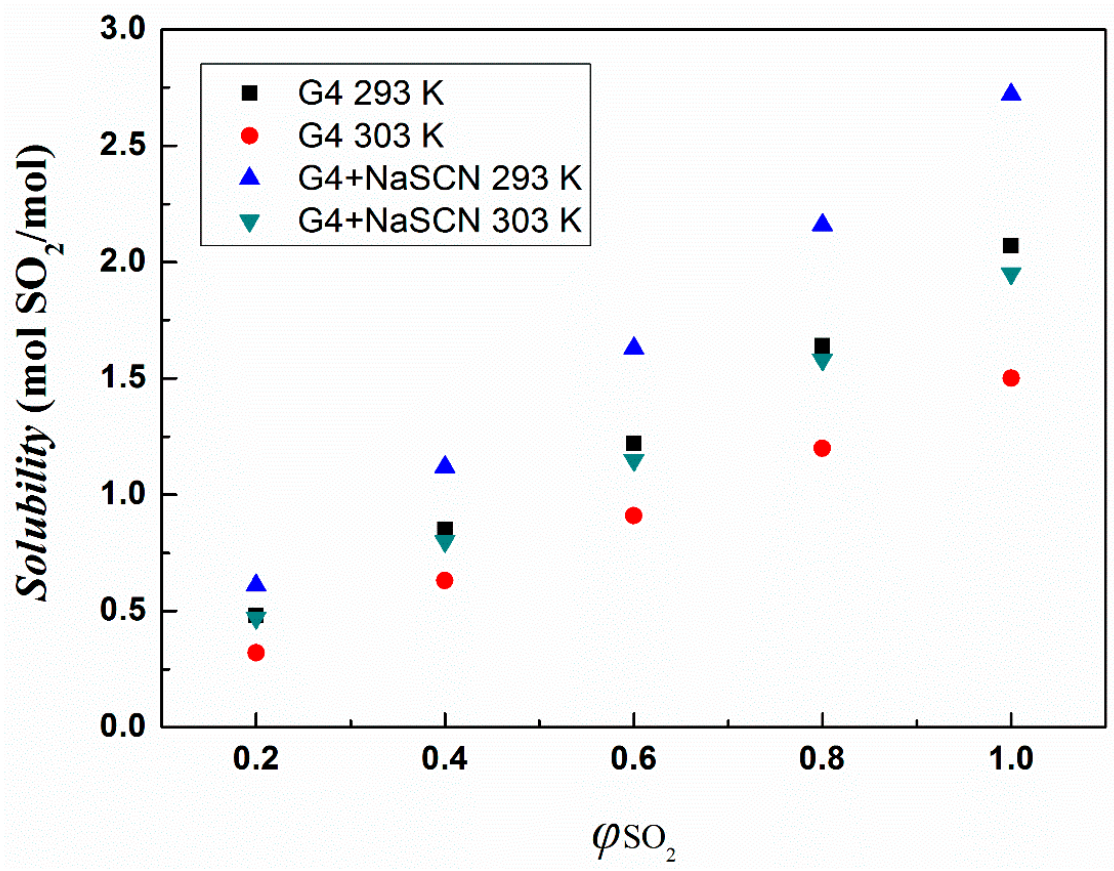

Figure 7. $\mathrm{SO}_{2}$ absorption capacities of tetraglyme and [Na-tetraglyme][SCN] at different $\mathrm{SO}_{2}$ partial pressures.

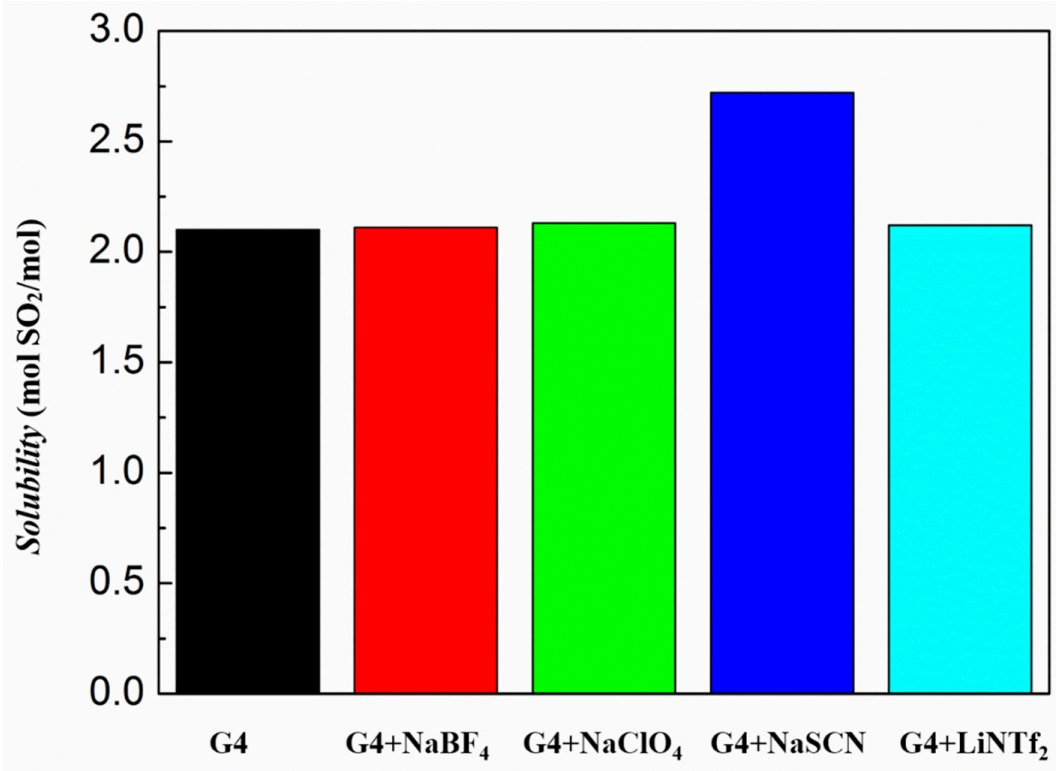

Figure 8. $\mathrm{SO}_{2}$ absorption capacities of tetraglyme, [Li-tetraglyme][ $\left.\mathrm{NTf}_{2}\right]$ ionic liquid, and [Na-tetraglyme][X] ionic liquids at $293 \mathrm{~K}$ and 1 bar $\left(\mathrm{X}=\mathrm{BF}_{4}, \mathrm{ClO}_{4}\right.$, and $\left.\mathrm{SCN}\right)$.

\subsection{Regeneration}

Tetraglyme and [Na-tetraglyme][SCN] ionic liquid were also used in absorption and regeneration tests, as shown in Figure 9. The result shows that regardless of tetraglyme and the ionic liquid, the solvents maintain good absorption and regeneration performance, and the $\mathrm{SO}_{2}$ absorption capacity of the ionic liquid is always higher than that of tetraglyme by about $30 \%$. In all the five cycles, both tetraglyme and the ionic liquid have a low sulfur dioxide content after the regeneration. The difference of $\mathrm{SO}_{2}$ content in the solvents in the absorbing/regenerating cycles can lead to the conclusion that [Na-tetraglyme][SCN] ionic liquid is more effective for future applications than tetraglyme. 


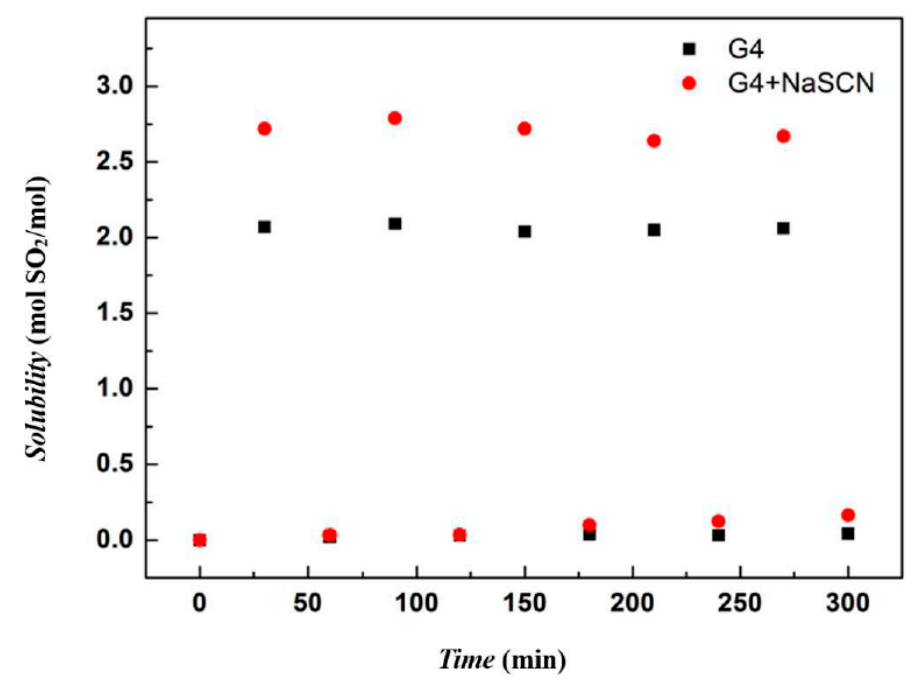

Figure 9. $\mathrm{SO}_{2}$ absorption capacities of tetraglyme and [Na-tetraglyme][SCN] over five absorption-desorption cycles.

\subsection{Mechanism}

$\mathrm{IR},{ }^{1} \mathrm{H}-\mathrm{NMR}$, and ${ }^{13} \mathrm{C}-\mathrm{NMR}$ were applied to further investigate the interaction between these ionic liquids and $\mathrm{SO}_{2}$. The IR spectral result shows that no new peak appeared after the absorption of $\mathrm{SO}_{2}$ (seen in Figure 4), i.e., no new chemical bond is formed. This means that there is no chemical interaction between $\mathrm{SO}_{2}$ and the sodium salt ionic liquid, which is consistent with the previous experimental results and is consistent with the conclusions from the literature on the absorption of tetraglyme [9]. That is to say, the formation of ionic liquids does not fundamentally change the nature of absorption.

The ${ }^{1} \mathrm{H}-\mathrm{NMR}$ result in Figure 2 shows that the chemical shift changes of tetraglyme and [Na-tetraglyme][SCN] ionic liquid are similar after absorption of $\mathrm{SO}_{2}$, which means that tetraglyme and [Na-tetraglyme][SCN] ionic liquid have the similar mechanism of interaction between the solvents and $\mathrm{SO}_{2}$, based on the charge-transfer interaction between sulfur atoms in $\mathrm{SO}_{2}$ and oxygen atoms in tetraglyme. The ${ }^{13} \mathrm{C}-\mathrm{NMR}$ result in Figure 3 further confirms this mechanism. Only the chemical shift belonging to the carbon atoms in $\mathrm{SCN}^{-}$moves after $\mathrm{SO}_{2}$ absorption. This means there is no obvious interaction between the carbon atoms in tetraglyme and $\mathrm{SO}_{2}$. However, the carbon atom in $\mathrm{SCN}^{-}$ moves upfield after the absorption of $\mathrm{SO}_{2}$, which suggests that there is Van der Waals' force between $\mathrm{SO}_{2}$ and $\mathrm{SCN}^{-}$. In other words, $\mathrm{SCN}^{-}$plays a significant role in the $\mathrm{SO}_{2}$ absorption process of the [Na-tetraglyme][SCN] ionic liquid.

\section{Conclusions}

In conclusion, a series of tetraglyme-sodium salt ionic liquids were prepared. Their structures were characterized, and their absorption capacities of $\mathrm{SO}_{2}$ were tested. In addition, the interaction between $\mathrm{SO}_{2}$ and the ionic liquids were investigated. The formed [Na-tetraglyme] ${ }^{+}$can not only significantly improve the thermal stability of the solvent but also effectively reduce solvent volatilization. It is clear that the ionic liquids mentioned above, especially [Na-tetraglyme][SCN] ionic liquid, are excellent $\mathrm{SO}_{2}$ absorbents, considering both the good absorption and impressive regeneration performance. Moreover, ${ }^{1} \mathrm{H}-\mathrm{NMR},{ }^{13} \mathrm{C}-\mathrm{NMR}$, and IR were applied to analyze the absorption mechanism of $\mathrm{SO}_{2}$ absorption in these ionic liquids. The results suggest that charge-transfer interaction between sulfur atoms and oxygen atoms is the main force, and the Van der Waals' force between $\mathrm{SCN}^{-}$and $\mathrm{SO}_{2}$ also plays an important role. As a conclusion, tetraglyme-sodium salt ionic liquids with high thermal stability and excellent $\mathrm{SO}_{2}$ absorption capacity can be picked out as promising alternatives to the traditional $\mathrm{SO}_{2}$-absorbing agents in $\mathrm{SO}_{2}$ removal. 
Supplementary Materials: The following are available online. Figure S1: Mass spectrogram of [Na-tetraglyme][SCN] ionic liquid. Figure S2. Thermal gravimetric analysis of tetraglyme and [Na-tetraglyme][SCN]. (At the constant temperature of $373 \mathrm{~K}$ ). Figure $\mathrm{S} . \mathrm{SO}_{2}$ absorption capacities of tetraglyme and [Na-tetraglyme][SCN] at different $\mathrm{SO}_{2}$ partial pressures. $\left(\mathrm{SO}_{2}\right.$ was diluted by $\mathrm{N}_{2}$ or air). Figure $\mathrm{S}$. $\mathrm{SO}_{2}$ absorption capacities of [Na-tetraglyme][SCN] with different water contents at $293 \mathrm{~K}$ and 1 bar.

Author Contributions: Conceptualization, Q.X. and X.W.; methodology, Q.X. and J.X.; software, Q.X. and W.J.; validation, Q.X., W.J. and J.X.; formal analysis, Q.X. and X.W.; resources, X.W.; data curation, Q.X. and J.X.; writing —original draft preparation, Q.X. and W.J.; writing - review and editing, Q.X. and X.W.; visualization, Q.X.; supervision, X.W.; project administration, X.W.; funding acquisition, X.W.

Funding: This research received no external funding.

Acknowledgments: This work is supported by Boyuan Hengsheng High-Technology Co., Ltd., Beijing, China.

Conflicts of Interest: The authors declare no conflicts of interest.

\section{References}

1. Spengler, J.D.; Ferris, B.G., Jr.; Dockery, D.W.; Speizer, F.E. Sulfur dioxide and nitrogen dioxide levels inside and outside homes and the implications on health effects research. Environ. Sci. Technol. 1979, 13, 1276-1280. [CrossRef]

2. Xue, J.; Yuan, Z.; Griffith, S.M.; Yu, X.; Lau, A.K.; Yu, J.Z. Sulfate Formation Enhanced by a Cocktail of High $\mathrm{NO}_{x}, \mathrm{SO}_{2}$, Particulate Matter, and Droplet $\mathrm{pH}$ during Haze-Fog Events in Megacities in China: An Observation-Based Modeling Investigation. Environ. Sci. Technol. 2016, 50, 7325-7334. [CrossRef] [PubMed]

3. Renedo, M.J.; Fernandez, J. Preparation, Characterization, and Calcium Utilization of Fly Ash $/ \mathrm{Ca}(\mathrm{OH})_{2}$ Sorbents for Dry Desulfurization at Low Temperature. Ind. Eng. Chem. Res. 2002, 41, 2412-2417. [CrossRef]

4. Ma, X.; Kaneko, T.; Tashimo, T.; Yoshida, T.; Kato, K. Use of limestone for $\mathrm{SO}_{2}$ removal from flue gas in the semidry FGD process with a powder-particle spouted bed. Chem. Eng. Sci. 2000, 55, 4643-4652. [CrossRef]

5. Hansen, B.B.; Kiil, S.; Johnsson, J.E.; Sønder, K.B. Foaming in Wet Flue Gas Desulfurization Plants: The Influence of Particles, Electrolytes, and Buffers. Ind. Eng. Chem. Res. 2008, 47, 3239-3246. [CrossRef]

6. Van Dam, M.H.H.; Lamine, A.S.; Roizard, D.; Lochon, P.; Roizard, C. Selective sulfur dioxide removal using organic solvents. Ind. Eng. Chem. Res. 1997, 36, 4628-4637. [CrossRef]

7. de Kermadec, R.; Lapicque, F.; Roizard, D.; Roizard, C. Characterization of the $\mathrm{SO}_{2}-\mathrm{N}$-Formylmorpholine Complex: Application to a Regenerative Process for Waste Gas Scrubbing. Ind. Eng. Chem. Res. 2002, 41, 153-163. [CrossRef]

8. Zhang, J.B.; Zhang, P.Y.; Chen, G.H.; Han, F.; Wei, X.H. Gas-Liquid Equilibrium Data for the Mixture Gas of Sulfur Dioxide/Nitrogen with Ethylene Glycol at Temperatures from (298.15 to 313.15) K under Low Pressures. J. Chem. Eng. Data 2008, 53, 1479-1485. [CrossRef]

9. Sun, S.; Niu, Y.; Sun, Z.; Xu, Q.; Wei, X. Solubility properties and spectral characterization of sulfur dioxide in ethylene glycol derivatives. RSC Adv. 2015, 5, 8706-8712. [CrossRef]

10. Earle, M.J.; Esperança, J.M.; Gilea, M.A.; Lopes, J.N.; Rebelo, L.P.; Magee, J.W.; Seddon, K.R.; Widegren, J.A. The distillation and volatility of ionic liquids. Nature 2006, 439, 831-834. [CrossRef]

11. Haumann, M.; Riisager, A. Hydroformylation in room temperature ionic liquids (RTILs): Catalyst and process developments. Chem. Rev. 2008, 108, 1474-1497. [CrossRef] [PubMed]

12. Hallett, J.P.; Welton, T. Room-temperature ionic liquids. Solvents for synthesis and catalysis. Chem. Rev. 1999, 99, 2071-2084. [CrossRef] [PubMed]

13. Che, S.; Dao, R.; Zhang, W.; Lv, X.; Li, H.; Wang, C. Designing an anion-functionalized fluorescent ionic liquid as an efficient and reversible turn-off sensor for detecting $\mathrm{SO}_{2}$. Chem. Commun. 2017, 53, 3862-3865. [CrossRef] [PubMed]

14. Yokozeki, A.; Shiflett, M.B. Hydrogen purification using room-temperature ionic liquids. Appl. Energy 2007, 84, 351-361. [CrossRef]

15. Jalili, A.H.; Rahmati-Rostami, M.; Ghotbi, C.; Hosseini-Jenab, M.; Ahmadi, A.N. Solubility of $\mathrm{H}_{2} \mathrm{~S}$ in Ionic Liquids $[\mathrm{bmim}]\left[\mathrm{PF}_{6}\right],[\mathrm{bmim}]\left[\mathrm{BF}_{4}\right]$, and [bmim] [Tf $\left.{ }_{2} \mathrm{~N}\right]$. J. Chem. Eng. Data 2009, 54, 1844-1849. [CrossRef]

16. Revelli, A.L.; Mutelet, F.; Jaubert, J.N. Reducing of nitrous oxide emissions using ionic liquids. J. Phys. Chem. B 2010, 114, 8199-8206. [CrossRef] [PubMed] 
17. Jacquemin, J.; Gomes, M.F.C.; Husson, P.; Majer, V. Solubility of carbon dioxide, ethane, methane, oxygen, nitrogen, hydrogen, argon, and carbon monoxide in 1-butyl-3-methylimidazolium tetrafluoroborate between temperatures $283 \mathrm{~K}$ and $343 \mathrm{~K}$ and at pressures close to atmospheric. J. Chem. Thermodyn. 2006, 38, 490-502. [CrossRef]

18. Wu, W.; Han, B.; Gao, H.; Liu, Z.; Jiang, T.; Huang, J. Desulfurization of Flue Gas: $\mathrm{SO}_{2}$ Absorption by an Ionic Liquid. Angew. Chem. Int. Ed. 2004, 43, 2415-2417. [CrossRef]

19. Yu, G.; Chen, X. SO 2 Capture by Guanidinium-Based Ionic Liquids: A Theoretical Study. J. Phys. Chem. B 2011, 115, 3466-3477. [CrossRef]

20. Shang, Y.; Li, H.; Zhang, S.; Xu, H.; Wang, Z.; Zhang, L.; Zhang, J. Guanidinium-based ionic liquids for sulfur dioxide sorption. Chem. Eng. J. 2011, 175, 324-329. [CrossRef]

21. Huang, J.; Riisager, A.; Wasserscheid, P.; Fehrmann, R. Reversible physical absorption of $\mathrm{SO}_{2}$ by ionic liquids. Chem. Commun. 2006, 38, 4027-4029. [CrossRef] [PubMed]

22. Shiflett, M.B.; Yokozeki, A. Separation of Carbon Dioxide and Sulfur Dioxide Using Room-Temperature Ionic Liquid [bmim][MeSO 4 ]. Energy Fuels 2009, 24, 1001-1008. [CrossRef]

23. Tian, S.D.; Hou, Y.C.; Wu, W.Z.; Ren, S.H.; Zhang, C. Absorption of $\mathrm{SO}_{2}$ by thermal-stable functional ionic liquids with lactate anion. RSC Adv. 2013, 3, 3572-3577. [CrossRef]

24. Ren, S.H.; Hou, Y.C.; Wu, W.Z.; Liu, Q.Y.; Xiao, Y.F.; Chen, X.T. Properties of Ionic Liquids Absorbing $\mathrm{SO}_{2}$ and the Mechanism of the Absorption. J. Phys. Chem. B 2010, 114, 2175. [CrossRef] [PubMed]

25. Huang, K.; Wang, G.N.; Dai, Y.; Wu, Y.T.; Hu, X.B.; Zhang, Z.B. Dicarboxylic acid salts as task-specific ionic liquids for reversible absorption of $\mathrm{SO}_{2}$ with a low enthalpy change. RSC Adv. 2013, 3, 16264-16269. [CrossRef]

26. Zeng, S.J.; Gao, H.S.; Zhang, X.C.; Dong, H.F.; Zhang, X.P.; Zhang, S.J. Efficient and reversible capture of $\mathrm{SO}_{2}$ by pyridinium-based ionic liquids. Chem. Eng. J. 2014, 251, 248-256. [CrossRef]

27. Huang, K.; Chen, Y.L.; Zhang, X.M.; Xia, S.; Wu, Y.T.; Hu, X.B. $\mathrm{SO}_{2}$ absorption in acid salt ionic liquids/sulfolane binary mixtures: Experimental study and thermodynamic analysis. Chem. Eng. J. 2014, 237, 478-486. [CrossRef]

28. Qu, G.F.; Zhang, J.; Li, J.Y.; Ning, P. $\mathrm{SO}_{2}$ Absorption/Desorption Characteristics of Two Novel Phosphate Ionic Liquids. Sep. Sci. Technol. 2013, 48, 2876-2879. [CrossRef]

29. Yang, Z.Z.; He, L.N.; Zhao, Y.N.; Yu, B. Highly Efficient $\mathrm{SO}_{2}$ Absorption and Its Subsequent Utilization by Weak Base/Polyethylene Glycol Binary System. Environ. Sci. Technol. 2013, 47, 1598-1605. [CrossRef]

30. Zhang, L.H.; Zhang, Z.J.; Sun, Y.L.; Jiang, B.; Li, X.G.; Ge, X.H.; Wang, J.T. Ether-Functionalized Ionic Liquids with Low Viscosity for Efficient $\mathrm{SO}_{2}$ Capture. Ind. Eng. Chem. Res. 2013, 52, 16335-16340. [CrossRef]

31. Yokozeki, A.; Shiflett, M.B. Separation of Carbon Dioxide and Sulfur Dioxide Gases Using Room-Temperature Ionic Liquid [hmim][Tf ${ }_{2} \mathrm{~N}$ ]. Energy Fuels 2009, 23, 4701-4708. [CrossRef]

32. Wang, C.; Cui, G.; Luo, X.; Xu, Y.; Li, H.; Dai, S. Highly Efficient and Reversible $\mathrm{SO}_{2}$ Capture by Tunable Azole-Based Ionic Liquids through Multiple-Site Chemical Absorption. J. Am. Chem. Soc. 2011, 133, 11916-11919. [CrossRef] [PubMed]

33. Cui, G.K.; Zheng, J.J.; Luo, X.Y.; Lin, W.J.; Ding, F.; Li, H.R.; Wang, C.M. Tuning Anion-Functionalized Ionic Liquids for Improved $\mathrm{SO}_{2}$ Capture. Angew. Chem. Int. Ed. 2013, 52, 10620-10624. [CrossRef] [PubMed]

34. Wang, C.M.; Zheng, J.J.; Cui, G.K.; Luo, X.Y.; Guo, Y.; Li, H.R. Highly efficient $\mathrm{SO}_{2}$ capture through tuning the interaction between anion-functionalized ionic liquids and $\mathrm{SO}_{2}$. Chem. Commun. 2013, 49, 1166-1168. [CrossRef]

35. Sun, S.; Niu, Y.; Xu, Q.; Sun, Z.; Wei, X. Highly efficient sulfur dioxide capture by glyme-lithium salt ionic liquids. RSC Adv. 2015, 5, 46564-46567. [CrossRef]

36. Reuter, K.; Dankert, F.; Donsbach, C.; von Hänisch, C. Structural Study of Mismatched Disila-Crown Ether Complexes. Inorganics 2017, 5, 11. [CrossRef]

37. Bernazzani, L.; Borsacchi, S.; Catalano, D.; Gianni, P.; Mollica, V.; Vitelli, M.; Asaro, F.; Feruglio, L. On the interaction of sodium dodecyl sulfate with oligomers of poly (ethylene glycol) in aqueous solution. J. Phys. Chem. B 2004, 108, 8960-8969. [CrossRef]

38. Guchhait, B.; Gazi, H.a.; Kashyap, H.K.; Biswas, R. Fluorescence Spectroscopic Studies of (Acetamide + Sodium/Potassium Thiocyanates) Molten Mixtures: Composition and Temperature Dependence. J. Phys. Chem. B 2010, 114, 5066-5081. [CrossRef] 
39. Mandai, T.; Nozawa, R.; Tsuzuki, S.; Yoshida, K.; Ueno, K.; Dokko, K.; Watanabe, M. Phase diagrams and solvate structures of binary mixtures of glymes and Na salts. J. Phys. Chem. B 2013, 117, 15072-15085. [CrossRef]

40. Terada, S.; Mandai, T.; Nozawa, R.; Yoshida, K.; Ueno, K.; Tsuzuki, S.; Dokko, K.; Watanabe, M. Physicochemical properties of pentaglyme-sodium bis (trifluoromethanesulfonyl) amide solvate ionic liquid. Phys. Chem. Chem. Phys. 2014, 16, 11737-11746. [CrossRef]

Sample Availability: Samples of the compounds including tetraglyme, NaSCN and NaBF4 are available from the authors.

(C) 2019 by the authors. Licensee MDPI, Basel, Switzerland. This article is an open access article distributed under the terms and conditions of the Creative Commons Attribution (CC BY) license (http:/ / creativecommons.org/licenses/by/4.0/). 